\title{
microRNA-146a inhibits $G$ protein-coupled receptor-mediated activation of NF-KB by targeting CARD10 and COPS8 in gastric cancer
}

\author{
Stephanie Geisler Crone ${ }^{1}$, Anders Jacobsen ${ }^{2,3}$, Birgitte Federspiel ${ }^{4}$, Linda Bardram5, Anders Krogh²,
} Anders $\mathrm{H} \mathrm{Lund}^{6}$ and Lennart Friis-Hansen ${ }^{1 *}$

\begin{abstract}
Background: Gastric cancer is the second most common cause of cancer-related death in the world. Inflammatory signals originating from gastric cancer cells are important for recruiting inflammatory cells and regulation of metastasis of gastric cancer. Several microRNAs (miRNA) have been shown to be involved in development and progression of gastric cancer. miRNA-146a (miR-146a) is a modulator of inflammatory signals, but little is known about its importance in gastric cancer. We therefore wanted to identify targets of miR-146a in gastric cancer and examine its biological roles.

Results: The expression of miR-146a was evaluated by quantitative PCR (qPCR) and found up-regulated in the gastrin knockout mice, a mouse model of gastric cancer, and in 73\% of investigated human gastric adenocarcinomas. Expression of miR-146a by gastric cancer cells was confirmed by in situ hybridization. Global analysis of changes in mRNA levels after miR-146a transfection identified two transcripts, caspase recruitment domain-containing protein 10 (CARD10) and COP9 signalosome complex subunit 8 (COPS8), as new miR-146a targets. qPCR, Western blotting and luciferase assays confirmed these transcripts as direct miR-146a targets. CARD10 and COPS8 were shown to be part of the G protein-coupled receptor (GPCR) pathway of nuclear factor-kappaB (NF-kappaB) activation. Lysophosphatidic acid (LPA) induces NF-kappaB activation via this pathway and over-expression of miR-146a inhibited LPA-induced NF-kappaB activation, reduced LPA-induced expression of tumor-promoting cytokines and growth factors and inhibited monocyte attraction.
\end{abstract}

Conclusions: miR-146a expression is up-regulated in a majority of gastric cancers where it targets CARD10 and COPS8, inhibiting GPCR-mediated activation of NF-kappaB, thus reducing expression of NF-kappaB-regulated tumor-promoting cytokines and growth factors. By targeting components of several NF-kappaB-activating pathways, miR-146a is a key component in the regulation of NF-kappaB activity.

Keywords: Stomach cancer, Non-coding RNA, Cytokines

\section{Background}

Globally gastric cancer is the second most common cause of cancer-related death [1]. Development of gastric cancer is influenced by interactions between host, environmental and bacterial factors. Examples of synergistic risk factors for gastric cancer are polymorphisms in genes involved in the host inflammatory response [2],

\footnotetext{
* Correspondence: Ifh@rh.dk

${ }^{1}$ Genomic Medicine, Rigshospitalet, University of Copenhagen, Rigshospitalet, Blegdamsvej 9, Copenhagen DK2100, Denmark

Full list of author information is available at the end of the article
}

Helicobacter pylori (H. pylori) virulence factors [3] and diets rich in salt and nitrate [4]. Despite recent progress in detection and treatment of early gastric cancer, the long-term survival rate for advanced gastric cancer is low [5]. The main challenges in treatment of advanced gastric cancer are lymphatic, peritoneal or distant organ metastases, which simultaneously predict poor outcome for these patients [6].

Although many oncogenes and tumor suppressors have been reported to be involved in development of gastric carcinomas, the molecular mechanisms underlying

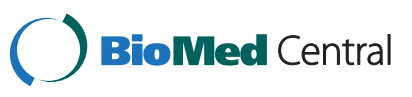


metastasis of advanced gastric carcinomas are still poorly understood [7]. One of the key events in gastric carcinogenesis is inflammation. Inflammation leads to activation of the transcription factor nuclear factorkappaB (NF-kB), which is associated with gastric carcinogenesis $[8,9]$.

microRNAs (miRNA) are involved in the development and progression of gastric cancer [10-13]. miRNA is a class of endogenous, non-coding, single-stranded RNA molecules of app. 22 nucleotides that mediate posttranscriptional regulation of gene expression through base pairing with the 3' untranslated region (UTR) of target messenger RNA (mRNA) [14]. miRNAs are involved in regulation of most cellular processes including cell proliferation, migration, differentiation and apoptosis [10,14,15]. miRNAs are aberrantly expressed in most human cancers and, like protein-coding genes, miRNAs can function as either tumor suppressors or oncogenes, thereby regulating carcinogenesis [10,12]. miRNA-146a (miR-146a) is regulated by NF-kB and inhibits interleukin-1 receptor (IL-1R) and toll-like receptor (TLR)- induced activation of NF- $\mathrm{kB}$ by targeting interleukin-1 receptor-associated kinase 1 (IRAK1) and TNF receptor associated factor 6 (TRAF6) [16-18]. miR$146 \mathrm{a}$ has been reported aberrantly expressed in several inflammatory diseases and cancers, but the role of miR$146 a$ in gastric cancer is still controversial, as expression of miR-146a has been found both up- and downregulated here [19-24]. Therefore, we investigated the expression of miR-146a in gastric cancer and characterized its targets and molecular functions to clarify the contradictory findings.

We found that miR-146a is up-regulated in a mouse model of gastric cancer as well as in human gastric adenocarcinomas and identified CARD10 and COPS8 as new direct targets of miR-146a. Both are part of the $G$ protein-coupled receptor (GPCR)-mediated signal transduction that mediates activation of NF- $\mathrm{kB}$. This suggests that miR-146a acts tumor suppressing by inhibiting GPCR-mediated activation of NF- $\mathrm{KB}$ and the resulting expression of tumor-promoting cytokines and growth factors.

\section{Results}

miR-146a expression is up-regulated in a mouse model of gastric cancer and in human gastric adenocarcinomas

Gastrin knockout (KO) mice are achlorhydric and develop intestinal metaplasia and gastric adenomas over time [25]. Using quantitative PCR (qPCR) we found the expression of miR-146a app. 2-fold up-regulated in old gastrin $\mathrm{KO}$ mice with either fundic intestinal metaplasia or antral adenoma compared to the expression in wild type (WT) mice $(\mathrm{P}<0.05)$ (Figure $1 \mathrm{~A})$. Using in situ hybridization miR-146a was detected in metaplastic gastric tissue from the gastrin $\mathrm{KO}$ mice, but not in normal gastric tissue from the WT mice (Figure 2AB) (Additional file 1: Figure S1). Having established that miR-146a is increased in our mouse model of gastric cancer we examined expression of miR-146a in paired human gastric adenocarcinomas and adjacent control biopsies and found that it was up-regulated in 27 out of 37 cases (73\%) (Figure 1B). In situ hybridization showed that miR-146a was expressed by the human gastric adenocarcinoma cells, while miR-146a-positive cells were not detected in the normal gastric mucosa (Figure 2CD) (Additional file 1: Figure S1).

There was no correlation between miR-146a expression in gastric adenocarcinomas and patients' age, sex and localization or classification of tumors (data not shown). Although patients with high miR-146a expression seemed to have a better overall survival this was not significant (Additional file 1: Figure S2).

\section{miR-146a targets members of the GPCR-mediated NF-KB activation pathway}

Having demonstrated increased expression of miR-146a in the majority of gastric cancers, we wanted to establish the biological actions of miR-146a by characterizing its direct molecular targets in human gastric cancer. We wanted to do this by over-expressing miR-146a in gastric cancer cells and then identifying mRNAs with reduced expression [26]. Therefore, we examined miR-146a expression in a panel of cell lines and found varied, but surprisingly low expression of miR-146a in the available gastric cell lines (Additional file 1: Figure S3), considering the detected over-expression in tumors.

The human gastric cancer cell line SNU638, which has neglectable levels of endogenous miR-146a was found suited for miR-146a over-expression studies. Since miR146a expression was very low in the tested gastric cell lines miR-146a inhibition studies were not conducted.

We first tested if over-expression of miR-146a affected the growth of the SNU638 cells and found cell growth unaffected (Additional file 1: Figure S4). Subsequently, global changes in gene expression in SNU638 cells following over-expression of miR-146a were examined. After miR-146a transfection mRNAs with predicted 3'UTR miR-146a target sites were significantly downregulated compared to mRNAs without predicted targets sites $(\mathrm{P}<4.6 \mathrm{e}-11$, two-tailed Wilcoxon rank-sum test) (Figure 3A). We analyzed all words of length 5-7 for over-representation in down-regulated mRNAs after miR-146a transfection and found the word strongest correlated with down-regulation was the seed site complementary to mature miR-146a bases 2-7/8 (Figure 3B). Transcripts with predicted 3'UTR miR-146a target sites that were significantly down-regulated upon miR-146a transfection were regarded as potential direct miR-146a 

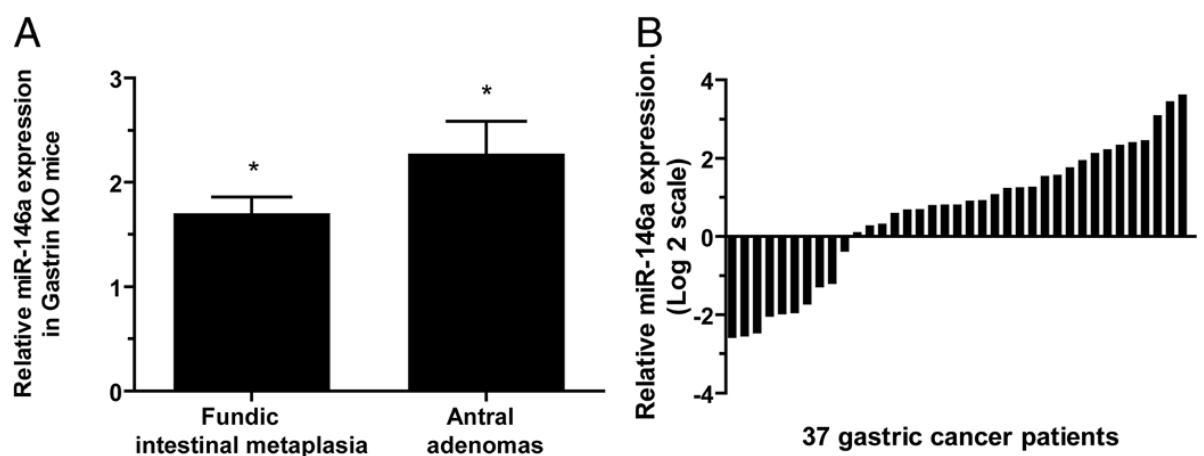

Figure 1 Increased expression of miR-146a in the gastrin KO mouse gastric cancer model and human gastric cancer. $(\boldsymbol{A})$ The relative expression of miR-146a in metaplastic fundic tissue $(n=8)$ and hyperplastic antral mucosa $(n=4) /$ antral adenomas $(n=4)$ from gastrin knockout $(\mathrm{KO})$ mice compared to the average expression in matching wild type (WT) mouse tissue. ${ }^{*}=\mathrm{P}<0.05$. (B) Waterfall plot of the expression of miR146a in 37 human gastric adenocarcinomas relative to the expression in adjacent normal tissue. miR-146a was up-regulated in 27 out of 37 tumors (73\%). The expression levels of miR-146a were determined by qPCR and normalized to those of the endogenous control RNU44.

targets. 847 matched these criteria (Additional file 1: Table S5). The top 10 most down-regulated potential miR-146a targets are shown in Figure 3C. As a negative validation control we repeated the procedure treating SNU638 cells with a miR-146a LNA inhibitor. There was no significant up-regulation of genes with the seed site complementary to mature miR-146a bases (data not shown).

The three most down-regulated genes upon miR146a over-expression, IRAK1, caspase recruitment domain-containing protein 10 (CARD10) and COP9 constitutive photomorphogenic homolog subunit 8 (COPS8) (Figure $3 \mathrm{C}$ ) all belong to signaling pathways leading to
NF- $\mathrm{KB}$ activation [27-29]. IRAK1 is a known miR-146a target involved in TLR- and IL-1R-mediated activation of NF- $k B$ [16-18]. CARD10 is involved in GPCR-mediated activation of NF- $\mathrm{kB}$ [27], while COPS8 is thought to be involved in this pathway based on its involvement in $\mathrm{T}$ cell receptor (TCR)-mediated NF- $k B$ activation [28]. Surprisingly, but similar to the findings of Boldin et al. [30], expression of TRAF6, which has previously been described as a miR-146a target $[16,18,31]$, was not reduced at the transcriptional level after miR-146a over-expression in our model system.

In gastric cancer, NF- $\mathrm{kB}$ modulates cell survival, immunity and inflammation, and NF- $\mathrm{kB}$ activation is

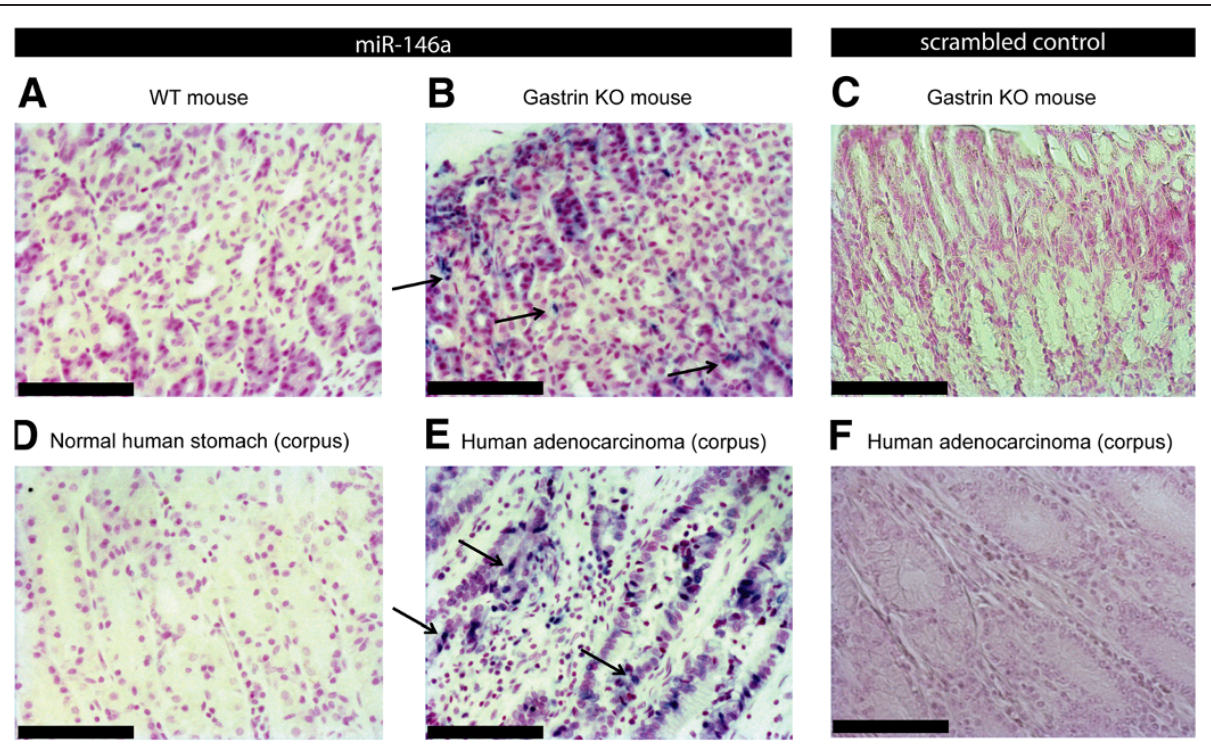

Figure 2 In situ hybridization detection of miR-146a expression in the gastrin KO mouse gastric cancer model and human gastric cancer. (A) Expression of miR-146a was not detected in WT fundic mouse tissue, (B) while miR-146a-positive cells (blue nuclei) were detected in the metaplastic fundic tissue from gastrin KO mice. (C) No signal was detected with the scrambled LNA probe. (D) miR-146a expression was absent in normal human gastric tissue, $(\boldsymbol{E})$ but present in human gastric adenocarcinoma cells (blue nuclei). (F) Negative control using a scrambled LNA probe. Representative miR-146a-positive cells are indicated by arrows. Original magnification x20, Scale bar =100 $\mu \mathrm{m}$. 


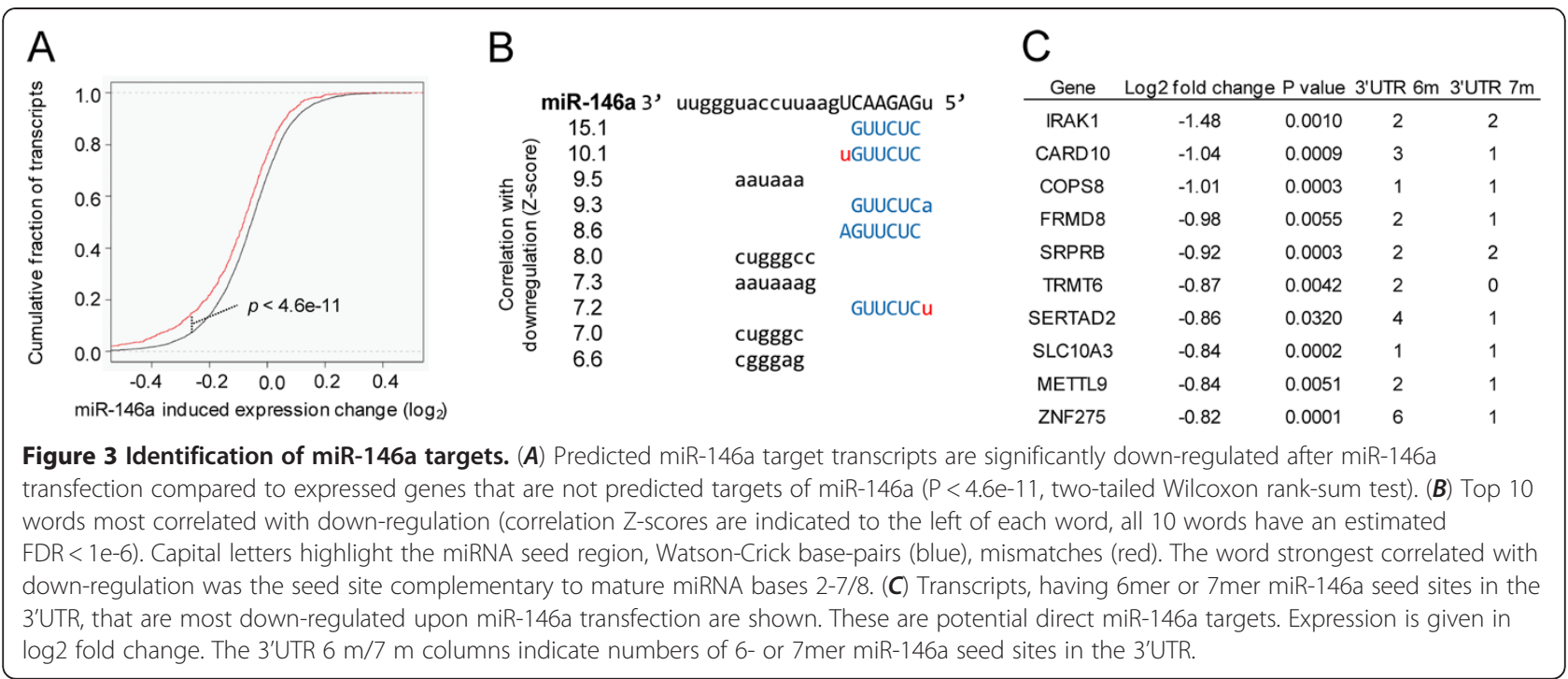

associated with poor outcome in gastric cancer [32,33]. We therefore focused on characterizing CARD10 and COPS8 as direct miR-146a targets and their roles in $\mathrm{NF}-\mathrm{\kappa B}$ activation in gastric cancer. We confirmed miR146a-mediated down-regulation of CARD10, COPS8 and IRAK1 at the transcript level (Figure 4A) and also found that miR-146a reduced levels of CARD10, COPS8 and IRAK1 protein (Figure 4B). Finally, direct targeting of miR-146a to 3'UTRs of the target genes was demonstrated using luciferase assays (Figure 4C). In summary, we confirmed earlier observations showing that miR146a directly targets IRAK1 and we furthermore identified two new targets, CARD10 and COPS8, which codes for proteins suggested to be involved in NF- $\mathrm{kB}$ activation. COPS8 is a component of the COP9 signalosome which consists of eight subunits (GPS1 and COPS2-8) [34]. COPS 8 is the only subunit targeted directly by miR-146, but since alteration in the amount of the individual subunits has been shown to affect the amount of other subunits $[35,36]$, we examined how transfection with miR146a affected expression of all COP9 signalosome components. In unstimulated cells the expression of COPS2 was reduced (20\%) (Additional file 1: Figure S5). We therefore assume that the effects of miR-146a on the COP9 complex mainly result from a reduction in COPS8 expression, although indirect destabilization of the complex cannot be ruled out.

\section{miR-146a inhibits GPCR-mediated NF-KB activity by targeting CARD10 and COPS8}

CARD10 and COPS8 are involved in GPCR-mediated activation of NF-kB $[28,29]$. We therefore wanted to establish their roles in signal transduction in gastric cancer and subsequently investigate the importance of
miR-146a for inhibiting this signaling. For this purpose we used lysophosphatiditc acid (LPA) which is a known activator of the GPCR-mediated NF- $k B$-activation pathway [29], and promotes gastric cancer cell migration and invasion [37]. LPA-stiumlation significantly increased NF$\kappa \mathrm{B}$ activity in our luciferase reporter system (Figure 5). siRNA knockdown of CARD10 and COPS8 expression significantly inhibited LPA-stimulated GPCR-mediated activation of NF-kB in SNU638 cells (Figure 5). This inhibition was comparable to the miR-146a-induced inhibition. In contrast, inhibiting endogenous miR-146a was without effect on NF-kB activation. As predicted, siRNA-mediated repression of IRAK1 expression did not affect LPAstimulated activation of NF- $\mathrm{kB}$ (Figure 5) as IRAK1 is not involved the GPCR-mediated pathway. As TRAF6 is a miR-146a target with a role in NF-kB activation, the effect of siRNA-mediated repression of TRAF6 expression on LPA-stimulated NF- $\mathrm{kB}$ activity was investigated. However, knockdown of TRAF6 did not inhibit LPA-stimulated NF$\kappa B$ activity (Figure 5). These results indicate that the two newly identified miR-146a targets, CARD10 and COPS8, are involved in GPCR-mediated activation of NF- $\mathrm{kB}$. Therefore, the effect of miR-146a over-expression on LPA-stimulated NF- $\mathrm{kB}$ activity was studied. miR-146a significantly inhibited LPA-stimulated NF- $\mathrm{KB}$ activity in SNU638 cells (Figure 5). A mix of siRNAs against CARD10, COPS8, IRAK1 and TRAF6 mimicked the miR146a-mediated inhibition of NF-kB activity (Figure 5). Knockdown of two other COP9 components (COPS2 and COPS5) also inhibited the LPA-stimulated NF-kB activity, demonstrating the importance of presence of all COP9 signalosome subunits for LPA-stimulated activation of NF- $\mathrm{kB}$. qPCR of the expression of the different components examined confirmed the knockdown (Figure 5). 


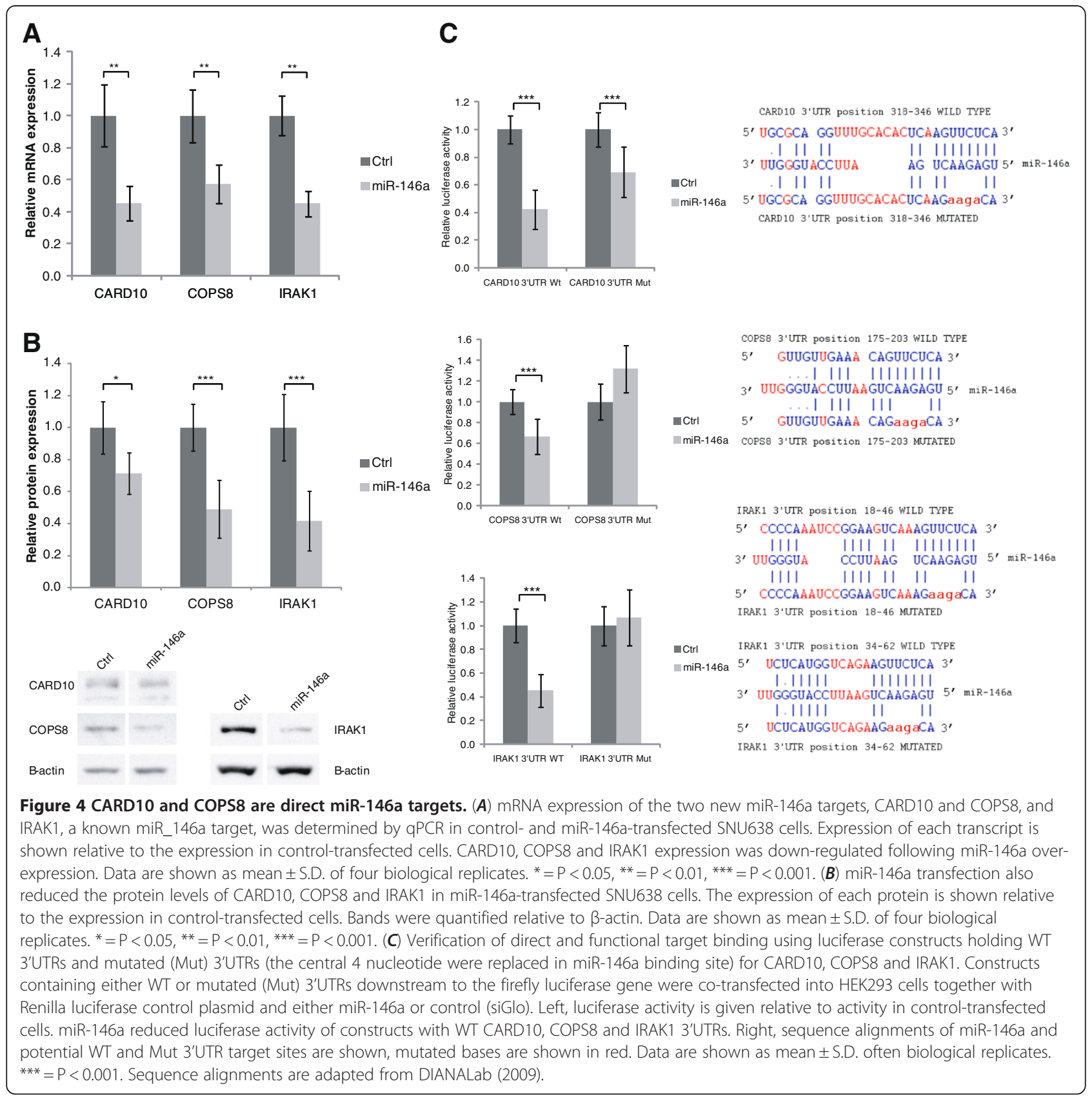

The expression of miR-146a is in part controlled by NF- $\mathrm{kB}$. We therefore also tested how the expression of miR-146a was affected by LPA and IL-1 $\beta$ stimulation. We found that LPA treatment doubled the expression of miR-146a and IL-1 $\beta$ stimulation gave a 4-fold increase in miR-146a expression, which is comparable to earlier observations [16,38] (Additional file 1: Figure S6). Although miR-146a LNA increased the expression of three of the miR-146a targets (TRAF6, IRAK1 and CARD10) (Figure 5) the overall activation of NF- $\mathrm{kB}$ was not altered in LPA-stimulated miR-146a LNA treated SNU638 cells.

\section{miR-146a reduces LPA-induced expression of cytokines} and growth factors

In most carcinomas microenvironmental factors rather than genetic alterations are probably responsible for activating $\mathrm{NF}-\mathrm{kB}$ signaling that regulates several processes including secretion of growth factors and cytokines $[39,40]$. Therefore, we investigated how miR-146a modulates expression of selected NF-kB-regulated growth factors and cytokines induced by extracelluar signals such as LPA. LPA-stimulation significantly increased expression of interleukin-6, -8, 23A (IL-6, IL-8, IL-23A) and chemokine (C-C motif) ligand 5 (CCL5), colony 


\section{miR-146a inhibits LPA stimulated $\mathrm{NF} \kappa \beta$ activation}

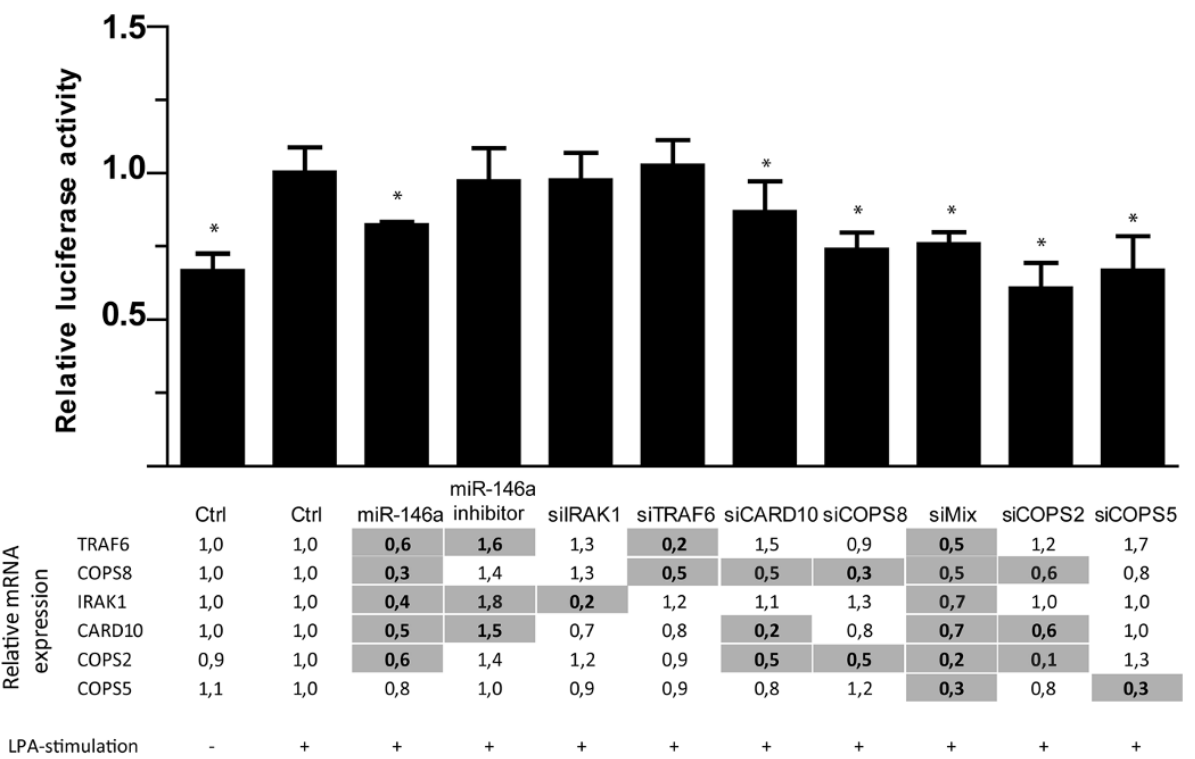

Figure 5 miR-146a targets COPS8 and CARD10 GPCR-mediated NF-KB activation. SNU638 cells were co-transfected with NF-KB reporter plasmid and Renilla luciferase control plasmid along with control (siGlo), siRNA or miR-146a. Cells were stimulated with 25 MM LPA and luciferase activity was measured. Luciferase activity is given relative to activity in control transfected LPA-stimulated cells. siRNA against CARD10 and COPS8, miR-146a, miR-146a inhibitor and a siRNA mix reduced luciferase activity. siRNA against IRAK1 and TRAF6 did not reduce luciferase activity. LPAstimulated NF-KB activation was also inhibited by siRNA against COPS2 and COPS5, demonstrating that other perturbation of the COP9 signalosome complex reduces GPCR-mediated NF-KB activation. siMix, mix of siRNAs against CARD10, COPS8, IRAK1 and TRAF6. Data are shown as the mean \pm S.D. of seven biological replicates. ${ }^{*}=P<0.05$. The relative expression of TRAF6, COPS8, IRAK1, CARD10, COPS2 and COPS5 was measured using $\mathrm{qPCR}$. Gray-shading indicates a significant change in expression, $p<0.05, n=4$.

stimulating factor 1 (macrophage) (CSF-1) and plateletderived growth factor beta polypeptide (PDGFB) in SNU638 cells (Figure 6). This confirmed that expression of these genes is regulated by LPA-induced NF- $\kappa \mathrm{B}$ activity. Over-expression of miR-146a significantly decreased expression of IL-8, IL-23A, CCL5, CSF-1 and PDGFB in SNU638 cells (Figure 6). Even though IL-6 is a target gene of NF-kB, and also upregulated by LPA miR-146a over-expression did not reduce IL- 6 expression under our conditions (Figure 6). However, LPA induction of IL-6 expression is not only mediated by NF- $\mathrm{kB}$ but also via other pathways (MAPK/ERK, PI3K/Akt, and p38) [41], which may contribute to the differences. In SNU638 cells the basal level of IL-6 is higher than IL-8, which may affect the mRNA turnover. This could be part of the reason that miR-146a has less effect on LPAstimulated IL-6 expression than on IL-8 expression, which has also been seen in other cellular systems [42].

miR-146a over-expression in SNU638 cells reduces recruitment of monocytes

In carcinomas monocytes can be recruited by e.g. CCL5 and CSF-1 expressed by tumor cells and this tumor infiltration of monocytes contributes to the tumorpromoting inflammatory response in the cancer $[39,40]$.

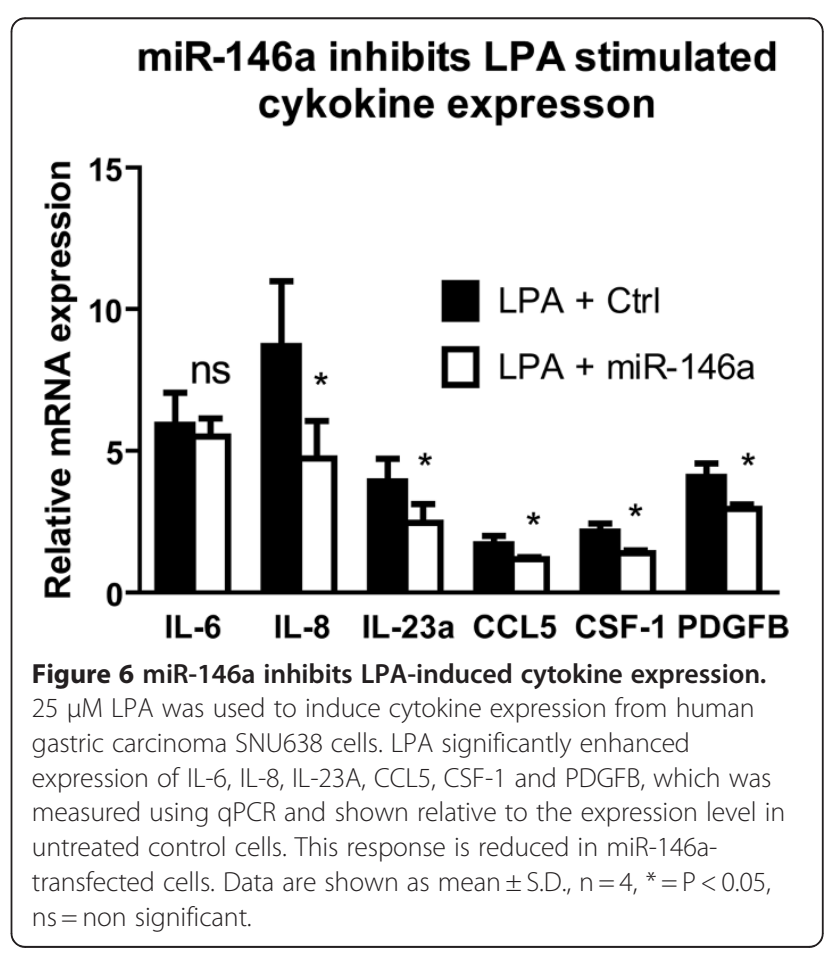


Having demonstrated that miR-146a reduced LPAinduced expression of cytokines, we examined how miR146a over-expression affected recruitment of monocytes. We found that LPA-treatment of SNU638 cells increased monocyte migration towards conditioned medium from the SNU638 cells (Figure 7 and Additional file 1: Figure S7), whereas transfection with miR-146a in part abrogated this response (Figure 7), again demonstrating that miR146a inhibits the biological responses of GPCR-mediated activation of NF-kB such as, recruitment of monocytes.

\section{Discussion}

Microenvironmental factors are important for NF-kB activation in inflammation-driven cancers such as gastric cancer and this NF- $\mathrm{KB}$ activation may provide cancer cells with advantages, which contribute to the tumorgenic processes [32,43]. Modulation of NF-kBactivating signaling is therefore important for controlling inflammation-mediated tumor development. Here, we show that miR-146a is a central negative regulator of NF- $\mathrm{kB}$ activation as it inhibits several NF- $\mathrm{B}$-activating pathways.

miR-146a expression was found up-regulated in app. $2 / 3$ of the human gastric adenocarcinomas as well as in the gastrin $\mathrm{KO}$ mouse model of gastric cancer. Similarly, expression of miR-146a has been found increased in cervical, breast, pancreatic and thyroid cancer [11,4446]. Previously, expression of miR-146a has been found both up- and down-regulated in gastric cancer [21-24]. These conflicting results may reflect differences in tumors and their microenvironment resulting in different degrees of NF- $\mathrm{kB}$ activities, which controls miR146a expression [16]. Surprisingly, we found low levels of miR-146a in human gastric cancer cell lines. This could indicate that the increased miR-146a levels seen in tumors are coursed by microenvironmental factors e.g. cells surrounding the tumor cells.

To examine the effects of increased miR-146a levels in gastric cancer we identified two new miR-146a targets, CARD10 and COPS8, and investigated the roles of these targets. We found that miR-146a inhibited GPCR-mediated NF- $\mathrm{B}$ activation by directly targeting and down-regulating expression of CARD10 and COPS8. CARD10 is known to be required for GPCRinduced activation of NF-kB $[27,29]$, while COPS8 is a subunit of COP9 signalosome that controls NF- $\mathrm{kB}$ activation $[28,47]$. We showed that CARD10 is involved in GPCR-mediated activation of NF- $\mathrm{BB}$, and provided new evidence that COPS8 is involved in this pathway as well. miR-146a over-expression also led to reduced expression of COPS2, another subunit of the COP9 signalosome. We assume that this is an indirect effect,

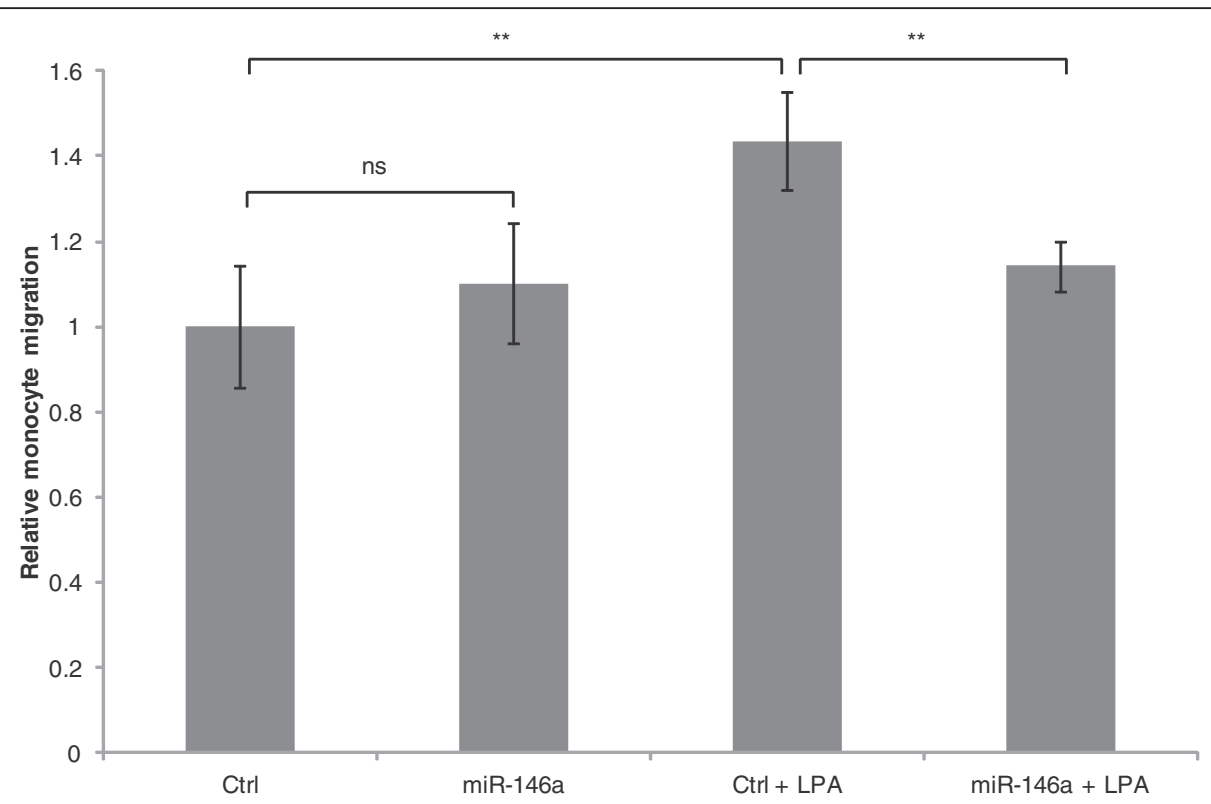

Figure 7 miR-146a reduces monocyte migration. Monocyte migration against conditioned medium from control- or miR-146a-transfected SNU638 cells that were left untreated or stimulated with $25 \mu \mathrm{M}$ LPA was followed over 8 hours. Migration of cells is shown relative to migration of untreated control cells. Monocyte migration against medium from LPA-stimulated SNU638 cells was increased compared to migration against medium from untreated cells, while monocyte migration against medium from miR-146a-transfected, LPA-stimulated cells was decreased compared to medium from control-transfected, LPA-stimulated cells. Data are shown as mean \pm S.D. of four biological replicates. ${ }^{* *}=P<0.01$, ns = non significant. 
since there is no miR-146a binding site in COPS2 3'UTR and changes in the expression of one subunit has been shown to affect that of the other [35,36]. It is therefore possible that miR-146a to some extent may act by not only targeting COPS8 but destabilizing the COP9 signalosome.

Aberrant signaling through GPCRs has been linked to tumor cell growth and survival, and NF-kB-activating GPCRs have been shown to contribute to a wide range of cancers (reviewed by Dorsam \& Gutkind [48]). GPCRs can activate NF-kB via the CARD10/BCL10/MALT1 complex after binding ligands such as LPA, enothelin-1, angiotensin II (Ang II) and chemokine (C-X-C motif) ligand 12 (CXCL12) (Figure 8) $[29,49]$. In our study we used LPA to model GPCR-mediated activation of NF- $\mathrm{kB}$. LPA-induced GPCR-signaling leads to tumor progression [49]. Thus, miR-146a-mediated inhibition of GPCR-signaling could have tumor suppressing effects.

In addition to GPCR-mediated NF- $\mathrm{BB}$ activation, NF$\kappa \mathrm{B}$ can be activated via tumor-necrosis-factor receptor (TNFR), IL-1R, TLR, TCR and B cell receptor (BCR) [50] (Figure 8). Previously, miR-146a has been shown to inhibit NF- $\mathrm{BB}$ activation via these receptors by downregulating expression of TRAF6 and IRAK1 [16,18,30,31]. miR-146a targets IRAK1 in gastric cancer cells, but not TRAF6. Although, we here show that miR146a targets GPCR-mediated activation of NF- $\mathrm{kB}$, in addition to the activation via TNFR, IL-1R, TLR, TCR and BCR, by targeting CARD10 and COPS8 (Figure 8). Thus, miR-146a targets multiple components of NF-kBactivating pathways in gastric cancer cells. This has not been shown for the NF-kB pathway before, but has previously been seen in the transforming growth factor- $\beta$ (TGF- $\beta$ ) pathway, where both miR-21 and the miR-1792 cluster target several mRNAs coding for proteins in the TGF- $\beta$ pathway $[51,52]$. By targeting multiple components of different NF- $\mathrm{kB}$-activating pathways miR146 a mediates a robust and complex control of NF- $\mathrm{kB}$ activity. Several other miRNAs can also regulate NF-kBsignaling, but only miR-146a targets several genes in different NF-kB-activating pathways, suggesting miR-146a as a key modulator of NF- $\mathrm{kB}$ activation.

NF- $\kappa \mathrm{B}$ regulates expression of cytokines and growth factors involved in several aspects of tumor progression

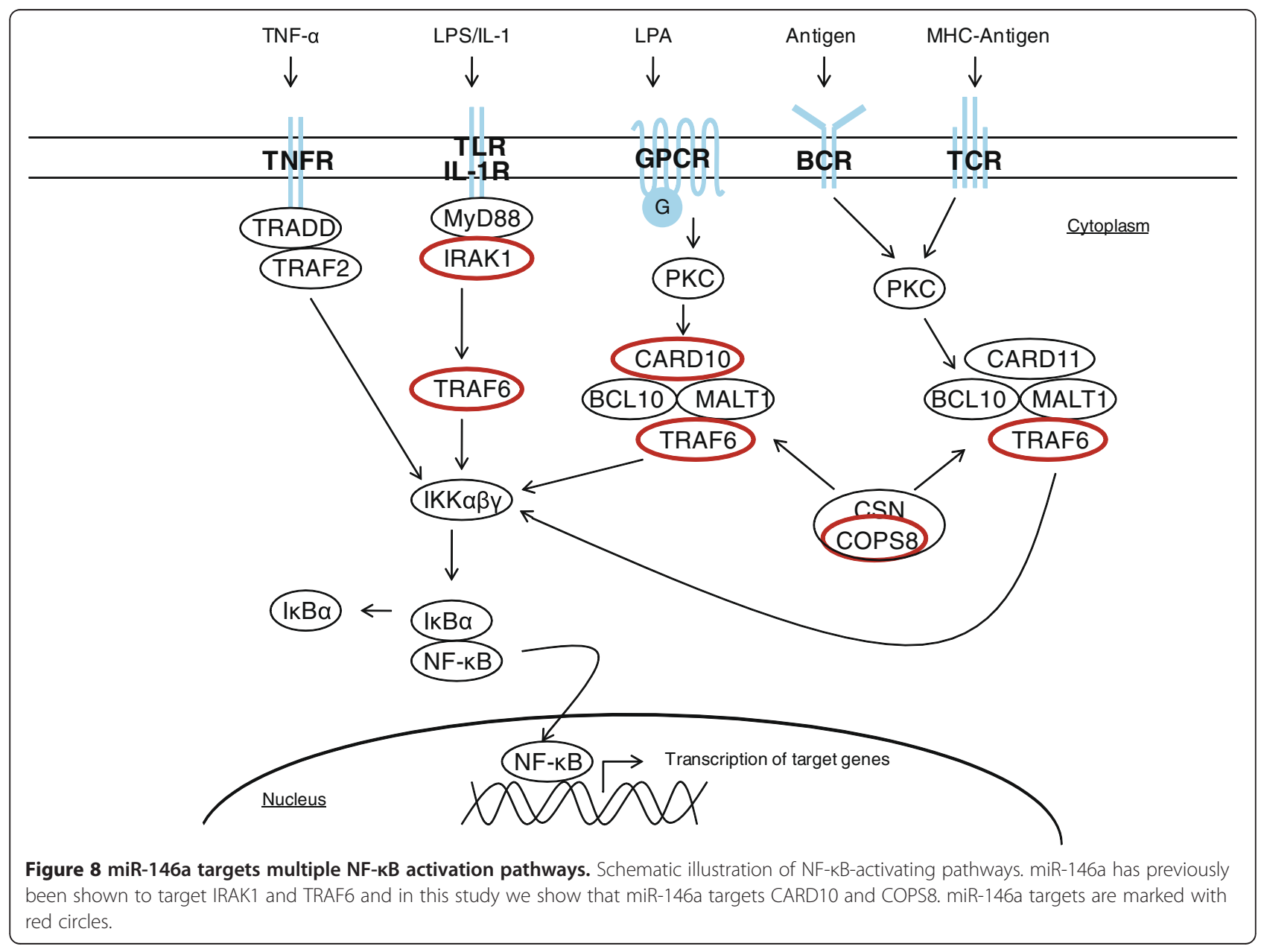


[43]. Given that miR-146a decreases NF-кB activity, it is possible that miR-146a acts tumor suppressing by reducing expression of such cytokines and growth factors. Indeed, we found that miR-146a over-expression reduced expression of several cytokines and growth factors with a known role in cancer development; IL-8, IL-23A, CCL5, CSF-1 and PDGFB. These genes can increase cell proliferation, cell adhesion and angiogenesis [53-55], contribute to tumor lymphangiogenesis [56], activate fibroblasts [57], recruit monocytes to tumors [39,40] and induce tumor-associated macrophages (TAMs) to secrete tumor-promoting mediators [58] (Figure 9).

Chemotactic cytokines released by tumor cells can recruit monocytes to tumor sites [39,59]. These monocytes can promote tumor progression [60]. CCL5 and CSF-1 are examples of monocyte-recruiting cytokines released by tumor cells $[39,40]$. As expected, monocytes migrated less against conditioned medium from LPA-stimulated SNU638 cells over-expressing miR-146a compared to LPA-stimulated control cells. Thus, miR-146a may reduce tumor infiltration of monocytes by decreasing tumor cell expression of cytokines.

Up-regulated levels of miR-146a in gastric cancer seen in this study could be caused by increased NF- $\kappa B$ activity in tumor cells. miR-146a is part of a negative feedback loop that inhibits NF- $\mathrm{B}$ activation in gastric cancer and the subsequent tumor-promoting processes. This is supported by a recent study that found low expression of miR-146a associated with poor survival of gastric cancer patients [22].

\section{Conclusions}

In summary, we have identified two new targets of miR146a, CARD10 and COPS8 that are both involved in GPCR-mediated activation of NF- $\mathrm{BB}$, and we have found that miR-146a inhibits secretion of chemokines and growth factors controlled by NF- $\mathrm{BB}$. With the addition of two new miR-146a targets we have shown that this miRNA targets several signal transduction pathways that activate NF-kB. Hence, we suggest that miR-146a act tumor-suppressing by inhibiting NF- $\mathrm{kB}$ activity and the consequently expression of tumor-promoting cytokines and growth factors.

\section{Methods}

Mice

Groups of WT and gastrin $\mathrm{KO}$ mice aged $1 \frac{1}{2}$ years were used. The mice were on a mixed 129/SvJ, C57BL/6J background backcrossed at least four times to C57BL/6J [25]. The mice were sacrificed by cervical dislocation. The stomachs were removed, washed gently in ice-cold PBS and the fundus was dissected from the stomach, frozen in liquid nitrogen and stored at $-80^{\circ} \mathrm{C}$ until RNA extraction. The mice were kept under specific pathogen-free conditions and monitored according to the Federation of European Laboratory Animal Science Associations recommendation [61]. The studies were approved by the

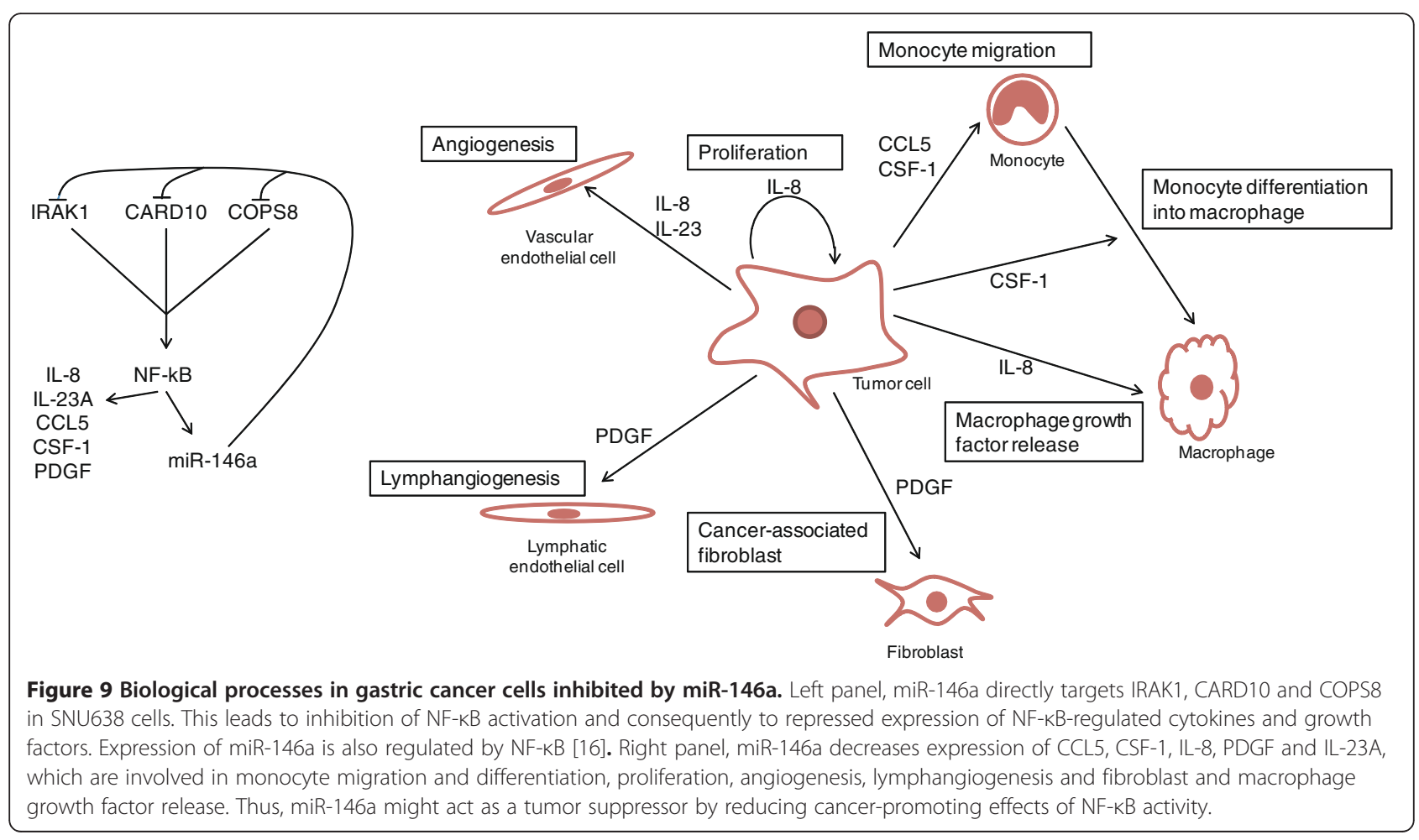


Danish Animal Welfare Committee (2005/562-40) and the Danish Forest and Nature Agency (20010077355/6).

\section{Human tissue samples}

Biopsies from human gastric adenocarcinomas and adjacent normal tissue were obtained from patients who underwent surgical resection at the Department of Gastrointestinal Surgery, Rigshospitalet, Copenhagen, Denmark, between July and December 2008. Collection of gastric cancer biopsies was approved by the Danish Ethical Committee (journal H-B-2008-049) and the establishment of a biobank was approved by Danish Data Protection Agency (journal 2008-41-2138). All procedures were in accordance with institutional ethical standards. All individuals provided written informed consent, and all samples were delinked and unidentified from their donors

\section{Cell culture and transfections}

SNU638 cells were grown in RPMI1640 medium (Invitrogen, Carlsbad, CA) and HEK293 cells in DMEM + GlutaMAX $^{\text {mu }}$-I (Invitrogen), both supplemented with 10\% Fetal Bovine Serum (Biowest, Nuaillé, France), penicillin $(100 \mathrm{U} / \mathrm{ml})$, streptomycin $(100 \mu \mathrm{g} / \mathrm{ml})$ (SigmaAldrich, Saint Louis, MI) and cefotaxim $(100 \mu \mathrm{g} / \mathrm{ml})$ (ACS Dobfar Generics S.A., Luxembourg, Belgium). Cells were cultured at $37^{\circ} \mathrm{C}$ in $5 \% \mathrm{CO}_{2}$. Where nothing else is stated cells were transfected using Turbofect ${ }^{\mathrm{m}}$ in vitro Transfection Reagent (Fermentas $\mathrm{GmbH}$, St. Leon-Rot, Germany). To over-express miR-146a in cultured cells $50 \mathrm{nM}$ Pre-miR ${ }^{\mathrm{ma}}$ miRNA Precursors for human miR-146a (hsa-miR-146a, Ambion, Invitrogen) were used and $50 \mathrm{nM}$ siGlo (Dharmacon, Lafayette, $\mathrm{CO}$ ) were used as negative control.

\section{RNA isolation}

Where nothing else is stated total RNA from tissue and cells was isolated using TRIzol ${ }^{\circledR}$ Reagent (Invitrogen).

\section{miR-146a over-expression analysis}

For mRNA microarrays SNU638 cells were transfected with miR-146a or siGlo using Lipofectamine2000 (Invitrogen). $24 \mathrm{~h}$ post-transfection total RNA was isolated. Affymetrix microarray analysis was performed at the Microarray Center, Rigshospitalet, Copenhagen, Denmark, using HG-U133 Plus 2.0 human arrays (Affymetrix, Santa Clara, CA) as previously described [62] and predicted miR-146a target genes were identified [63]. Briefly, $2 \mu \mathrm{g}$ of total RNA was used to synthesize double-stranded cDNA using Superscript Choice System (Invitrogen) with an oligo(dT) primer containing a T7 RNA polymerase promoter. Subsequently, cDNA was used as template for an in vitro transcription reaction generating biotin-labeled antisense cRNA (BioArrayTM
High Yield RNA Transcript Labeling kit; Enzo Diagnostics, Farmingdale, NY). Arrays were scanned in an Affymetrix GeneArray ${ }^{\circledR} 2500$ scanner and data were analyzed using D-chip MFC Application (software version 1.0.0.1). Three biological replicates of each transfection were analyzed. The microarray expression data were processed using the 'affy' package in BioConductor. Probeset intensities were summarized and quantile normalized using the RMA and VSN packages. Differential expression was determined per probe set using a t-test. The probe sets were mapped to Ensembl transcripts (version 49) using mappings obtained from BioMart. Probe sets that mapped ambiguously to different Ensembl genes were discarded. 3'UTRs were scanned for matching $6 \mathrm{mer}$, $7 \mathrm{mer}$ and $8 \mathrm{mer}$ miR-146a target sites (complementary to position $2-7,2-8$, and 2-9 of the miRNA sequence). To evaluate if predicted miR-146a targets were down-regulated after miR-146a transfection, we tested the null hypothesis that the expression change distribution of predicted miR-146a target genes (having a 7mer target site in the 3'UTR) was identical to the distribution of all expressed genes without predicted target sites using the non-parametric Wilcoxon rank-sum test. We used a previously published non-parametric rankbased statistic to perform an exhaustive and unbiased assessment of the correlation of 3'UTR word occurrences and the change in gene expression after miR146a transfection [63]. Genes were sorted by their expression change after miR-146a transfection, and the correlation with down-regulation was tested for all words of length 5-7 ( $\mathrm{N}=21504)$.

\section{Quantitative PCR}

Mature miR-146a expression was measured and quantified using TaqMan ${ }^{\circledR}$ MicroRNA Assay hsa-miR-146a (Applied Biosystems, Foster City, CA). For each biological sample technical triplicates were made. Analyses were carried out on the ABI Prism ${ }^{\circledR} 7900$ HT Sequence Detection System (SDS) (Applied Biosystems). miR-146a levels were normalized to the endogenous control RNU44 (Applied Biosystems).

For mRNA qPCR, total RNA from transfected cells was isolated and qPCR was performed using SuperScript $^{\text {mat }}$ III First-Strand Synthesis SuperMix (Invitrogen) and SYBR GreenER ${ }^{\text {mix }}$ qPCR SuperMix for ABI PRISM ${ }^{\circledR}$ (Invitrogen). The analyses were carried out on $\mathrm{ABI}$ Prism $^{\circledR}$ 7900HT SDS (Applied Biosystems). Primers were designed using primer3 (Additional file 1: Table S1) or predesigned primers (Quantitect, Qiagen, Hilden, Germany) were used. For each biological sample technical triplicates were made. Expression of target mRNA was normalized to GAPDH expression and quantified using standard curves. 


\section{In situ hybridization}

Gastric tissues from WT and gastrin $\mathrm{KO}$ mice were formalin-fixed and paraffin-embedded (FFPE). FFPE tissue samples of human gastric adenocarcinomas and normal gastric tissues were obtained from the Department of Pathology, Rigshospitalet, Copenhagen, Denmark. A DIG-labeled mercury locked nucleic acid miR-146a detection probe (Exiqon, Vedbæk, Denmark) was used for detection as described by Jørgensen et al. [64]. Probe concentration was $100 \mathrm{nM}$ and slides were hybridized at $50^{\circ} \mathrm{C}$. Pictures of representative areas of the slides were taken with a Zeiss Axio Imager (Zeiss, Jena, Germany), original magnification x20/10. Cells with intense blue nuclear stain were scored as positive. The level of expression within a positive cell was not scored. A LNA probe against snRNA U6 (Exiqon) was used as positive control and a scramble probe (Exiqon) as negative control.

\section{Western blotting}

For Western blotting SNU638 cells were transfected with miR-146a or siGlo and cells were harvested 6 and $72 \mathrm{~h}$ post-transfection. Proteins were separated on polyacrylamide gels, transferred to nitrocellulose membranes, incubated with antibodies against IRAK1 (4359, Cell Signaling Technology, Danvers, MA), CARD10 (ab64171, abcam, Cambridge, UK), COPS8 (ab77300, abcam) or $\beta$-actin (A2228, Sigma-Aldrich) and visualized by chemiluminescence (SuperSignal ${ }^{\circledR}$ West Pico, Pierce, Rockford, IL) using LAS-1000 Pro v. 2.6 (FujiFilm, Tokyo, Japan). Protein band intensities were quantified using Multi Gauge Software v. 3.1 (FujiFilm). $\beta$-actin was used as loading control.

\section{3'UTR luciferase assay}

3'UTR luciferase reporter plasmids were constructed by amplifying CARD10 and COPS8 3'UTR fragments containing potential miR-146a binding sites from human genomic DNA (primer sequences in Additional file 1: Table S2). Fragments were cloned into pMIR-REPORT Luciferase miR Expression Reporter Vector (Applied Biosystems) downstream of the Firefly luciferase gene. miR-146a seed sites were mutated by substitution of four nucleotides using QuickChange Site-Directed Mutagenesis Kit (Agilent Technologies, Palo Alto, CA), thereby changing the sequence from AGTTCTCA to AGAA GACA (mutagenesis primers in Additional file 1: Table S3). pMIR-REPORT plasmids containing WT and mutated IRAK1 3'UTR site were made by Taganov et al. [16] (Addgene plasmids 15095/15096). HEK293 cells were plated at $1 \times 10^{5}$ cells/well in 24-well plates and transfected $24 \mathrm{~h}$ later. HEK293 cells were used as they generally have low endogenous miRNA levels [65]. Each transfection reaction contained $10 \mathrm{ng}$ luciferase pMIRREPORT and 20 ng Renilla vector (pRL-TK, Promega,
Madison, WI) together with $50 \mathrm{nM}$ miR-146a (Ambion) or siGlo (Dharmacon). $24 \mathrm{~h}$ post-transfection Firefly luciferase and Renilla luciferase luminescence was measured using Dual-Glo luciferase kit (Promega) and a GloMax ${ }^{\circledR}-96$ luminometer (Promega). Background measurements were subtracted and ratios of Firefly luciferase luminescence from pMIR-REPORT relative to Renilla luciferase luminescence from pRL-TK were calculated.

\section{NF-кB activity assay}

SNU638 cells were plated at $1 \times 10^{5}$ cells/well in 24 -well plates and transfected after $24 \mathrm{~h}$. Each transfection reaction contained $500 \mathrm{ng}$ NF- $\mathrm{kB}$ luciferase reporter plasmid [66], 50 ng pRL-TK (Promega) and $50 \mathrm{nM}$ siGlo (Dharmacon), $50 \mathrm{nM}$ miR-146a (Ambion), $50 \mathrm{nM}$ miCURY miR-146a inhibitor (Exiqon) or $50 \mathrm{nM}$ siRNAs against CARD10, COPS8, IRAK1 or TRAF6 (Flexitube, Qiagen, Hilden, Germany). 24 h post-transfection cells were stimulated with $25 \mu \mathrm{M}$ LPA (Avanti Polar Lipids, Alabaster, AL). $24 \mathrm{~h}$ after stimulation Firefly luciferase and Renilla luciferase luminescence was measured as described above. Background measurements were subtracted and ratios of luminescence from NF- $\mathrm{kB}$ reporter plasmid relative to luminescence from pRL-TK were calculated.

\section{Monocyte migration}

Monocytes were isolated by density gradient centrifugation followed by plastic adherence. Peripheral blood mononuclear cells were isolated from blood from healthy donors by density centrifugation with Lymphoprep using a standard protocol (Axis-Shield Poc AS, Oslo, Norway) [67]. Cells were plated in plastic dishes and allowed to adhere for $1 \mathrm{~h}$. Non-adherent cells were washed away and adherent monocytes were used for migration studies. Monocytes were seeded in the upper chambers of CIM-plate 16 (Roche Diagnostics $\mathrm{GmbH}$, Manheim, Germany). $8 \times 10^{5}$ cells/well were seeded in RPMI1640 medium containing 1\%. Lower chambers contained conditioned medium from siGlo- or miR146a-transfected SNU638 cells that were left untreated or treated with $25 \mu \mathrm{M}$ LPA (Avanti Polar Lipids) for 6 hours. Migration was followed real-time over 8 hours with $\mathrm{xCELLigence} \mathrm{impedance} \mathrm{analysis} \mathrm{using} \mathrm{the} \mathrm{RTCA}$ DP instrument (Roche Diagnostics $\mathrm{GmbH}$ ). This method allows continuous measurement of cell migration by measuring the electrical impedance over gold electrodes incorporated on the underside of a microporous polyethylene terephthalate dividing an upper and lower. Migration rates were calculated using the RTCA software (Roche Diagnostics $\mathrm{GmbH}$ ).

\section{Statistical analysis}

Where nothing else is stated statistical analyses were performed using Student's unpaired two-tailed t-test 
calculated by Excel's ToolPak or GraphPad Prism Software. P-values less than 0.05 were considered significant. The patient overall survival from the day of surgery was examined using the Kaplan-Meier method, with log-rank test (Mantel-Cox test) and the Gehan-Breslow-Wilcoxon test for statistical significance.

\section{Additional files}

Additional file 1: Figure S1. Expression of miR-146a in the gastrin KO mice and in human gastric cancer. In situ hybridization detection of miR146a expression. ( $A$ and $B$ ) miR-146a expression was absent in WT fundic mouse tissue, while miR-146a-positive cells (blue nuclei) were detected in the metaplastic fundic tissue from gastrin KO mice. ( $C$ and D) miR-146a expression was absent in normal human gastric tissue, while human gastric adenocarcinoma cells stained for miR-146a (blue nuclei). Original magnification $\times 10$, Scale bar $=100 \mu \mathrm{m}$. Figure S2. Survival of gastric cancer patients with low or high tumor miR-146a expression. KaplanMeier overall survival curves according to miR-146a level. Although patients whose tumors have high expression of miR-146a seemed to have better survival than those with low expression, it was not significant, $p=0,31$ (Mantel-Cox Test). Low expression was defined as those with a relative miR-146a expression below the median expression and high expression had relative expression above median. Figure S3. Relative expression of miR-146a in cell lines. The expression of miR-146a in cells lines determined by qPCR. Gastric cancer cell lines are indicated by red bars. Relative miR-146a expression was determined using TaqMan $^{\circledR}$ MicroRNA Assay hsa-miR-146a according to the manufacturer's protocol (Applied Biosystems). miR-146a levels were normalized to hsamiR-191 (Applied Biosystems), which served as an endogenous control. Figure S4. Normal growth of SNU638 cells transfected with miR-146a in cell lines. 2,5 106 SNU638 cells were seeded in $10 \mathrm{~cm}$ petri dishes and transfected the following day with $50 \mathrm{nM}$ miR-146a, miCURY miR-146a inhibitor or Ctrl using Lipofectamine 2000 (Invitrogen). The following day the cell were transferred to 24-well plates where the cells were fixed at indicated time points in $4 \%$ paraformaldehyde, stained in a $0.1 \%$ crystal violet solution, and resuspended in $10 \%$ acetic acid. Sample absorbance was measured at $620 \mathrm{~nm}$, and normalized to that of siGlo control transfected cells. Mean \pm S.D. $n=4$ /day. Figure S5. Expression of the mammalian signalosome 8 subunits (GPS1 and COPS2-8) in SNU638 cells transfected with miR-146a. Alteration in the expression of one subunit has been reported to affect the expression of the others. Using $\mathrm{qPCR}$ the expression of the subunits (GPS1 and COPS2-8) was therefore examined in SNU638 cells transfected with miR-146a. Only COPS8 mRNA is a direct target of miR-146a, indicated by open bars. The absence of miR-146a target sites is indicated by closed bars. The expression of COPS8 and COPS2 was reduced following miR-146a transfection. Mean \pm S.D. ${ }^{*}=p<0.05, n=4$. COPS 8 mRNA is directly targeted by miR-146a, while we assume that the expression of COPS2 is indirectly affected by miR146a since the mRNA does not contain a miR-146a target site. Figure S6. Up-regulation of miR-146a in response to cancer-related cytokines. SNU638 cells were grown in media with $1 \%$ FCS overnight and subsequently stimulated with either LPA $(10 \mu \mathrm{M}), \mathrm{LL}-1 \beta(10 \mathrm{ng} / \mathrm{ml})$ or vehicle for $6 \mathrm{~h}$. The expression of miR-146a was measured by $\mathrm{qPCR}$ and normalized to the expression of U44. miR-146a expression is shown relative to the average expression in the control. Data are the mean \pm S.D. $(n=4)$. Figure S7. Monocyte migration Boyden chamber assay. Monocyte migration against conditioned medium from control- or miR-146atransfected SNU638 cells that were left untreated or stimulated with $25 \mu \mathrm{M}$ LPA was followed over 6 hours. Monocyte migration against medium from LPA-stimulated SNU638 cells was increased compared to migration against medium from untreated cells, while monocyte migration against medium from miR-146a-transfected, LPA-stimulated cells was decreased compared to medium from control-transfected, LPAstimulated cells. Data are shown as mean \pm S.D, $n=3,{ }^{*}=P<0.05$. Monocytes were isolated as described. Monocytes were seeded in the upper chambers of Boyden chamber assay (Becton Dickinson, Heidelberg, Germany), 2.5×104 cells/well were seeded in RPMI1640 medium containing 1\%. The lower chambers contained conditioned medium from SNU638 cells that had been transfected with Ctrl, miR-146a, or miCURY-miR-146a inhibitor and the following day left untreated or treated with $25 \mu \mathrm{M}$ LPA (Avanti Polar Lipids) for 6 hours $(n=3)$. After 120 minute incubation in $5 \% \mathrm{CO} 2$ at $37^{\circ} \mathrm{C}$, non-migrating cells were scraped from the upper surface of the filter using a cotton plug. Cells on the lower surface were fixed with methanol and stained with methylene blue. The number of cells on the lower surface of the filter was determined microscopically by counting 3 high-power (x400) fields of constant area per well. To normalize all experiments, values were expressed as the fraction of number of cells that migrated through in the unconditioned control. Mean \pm S.D. Table S1 mRNA qRT-PCR primers (TAG Copenhagen, Copenhagen, Denmark). Table S2 3'UTR luciferase primers. Restriction sites are indicated with lower case lettters (TAG Copenhagen). Table S3 Mutagenesis primers. Table 4 Transcripts with predicted 3'UTR miR-146a target sites that were significantly downregulated upon miR-146a transfection.

\section{Abbreviations}

BCR: B cell receptor; CARD10: Caspase recruitment domain-containing protein 10; CCL: Chemokine (C-C motif) ligand; COPS8: COP9 signalosome complex subunit 8; CSF-1: Colony stimulating factor 1 (macrophage); FFPE: Formalin-fixed and paraffin-embedded; GPCR: G Protein-coupled receptors; IL: interleukin; IL-1R: Interleukin-1 receptor; IRAK1: interleukin-1 receptor-associated kinase 1 ; KO: knockout; LPA: Lysophosphatidic acid; miR146a: microRNA-146a; miRNA: microRNA; mRNA: Messenger RNA; NFKB: nuclear factor-kappaB; PDGFB: Platelet-derived growth factor beta polypeptide; TAM: Tumor-associated macrophages; TCR: T cell receptor; TGF: Transforming growth factor; TLR: Toll-like receptor; TNFR: Tumornecrosis-factor receptor; TRAF6: TNF receptor associated factor 6; UTR: Untranslated region; WT: Wild type.

\section{Competing interests}

The authors declare that they have no competing interests.

\section{Authors' contributions}

Study concept and design: SGC, AHL, AK, LFH. Acquisition of data: SGC, AJ, $B F, L B, L F H$. Analysis and interpretation of data: SGC, AJ, AK, LFH. Drafting of the manuscript: SGC, LFH. Critical revision of the manuscript for important intellectual content: SGC, AK, AHL, LB, AJ, LFH. Statistical analysis: SGC, AJ. Obtained funding: SGC, LFH. Administrative, technical, or material support: SGC, BF, LB, LFH. Study supervision: LFH, AHL. All authors read and approved the final manuscript.

\section{Acknowledgements}

Ewa Futroma-Kazmierczak and Mette Hedegaard Moldaschl are thanked for their skilful technical assistance.

\section{Funding}

This study was supported by the Danish MRC (LFH), The Novo Nordic Foundation (LFH), Rigshospitalet's MRC (SGC).

\section{Author details}

${ }^{1}$ Genomic Medicine, Rigshospitalet, University of Copenhagen, Rigshospitalet, Blegdamsvej 9, Copenhagen DK2100, Denmark. ${ }^{2}$ Bioinformatics Centre, Institute of Molecular Biology, University of Copenhagen, Copenhagen, Denmark. ${ }^{3}$ Computational Biology Center, Memorial Sloan-Kettering Cancer Center, New York, NY, USA. ${ }^{4}$ Dept. of Pathology, Rigshospitalet, University of Copenhagen, Copenhagen, Denmark. ${ }^{5}$ Dept. of Surgical Gastroenterology, Rigshospitalet, University of Copenhagen, Copenhagen, Denmark. ${ }^{6} \mathrm{BRIC}$ Biotech Research \& Innovation Centre and Centre for Epigenetics, University of Copenhagen, Copenhagen, Denmark.

Received: 8 February 2012 Accepted: 18 September 2012 Published: 20 September 2012

\section{References}

1. Crew KD, Neugut Al: Epidemiology of gastric cancer. World J Gastroenterol 2006, 12:354-362. 
2. Persson C, Canedo P, Machado JC, El-Omar EM, Forman D: Polymorphisms in inflammatory response genes and their association with gastric cancer: A HuGE systematic review and meta-analyses. Am J Epidemiol 2011, 173:259-270.

3. Yamaoka Y: Mechanisms of disease: Helicobacter pylori virulence factors. Nat Rev Gastroenterol Hepatol 2010, 7:629-641.

4. Peleteiro B, Lopes C, Figueiredo C, Lunet N: Salt intake and gastric cancer risk according to Helicobacter pylori infection, smoking, tumour site and histological type. Br J Cancer 2011, 104:198-207.

5. Hohenberger P, Gretschel S: Gastric cancer. Lancet 2003, 362:305-315.

6. Cappetta A, Lonardi S, Pastorelli D, Bergamo F, Lombardi G, Zagonel V: Advanced gastric cancer (GC) and cancer of the gastro-oesophageal junction (GEJ): focus on targeted therapies. Crit Rev Oncol Hematol 2012, 81:38-48.

7. Oue N, Hamai Y, Mitani Y, Matsumura S, Oshimo Y, Aung PP, Kuraoka K, Nakayama H, Yasui W: Gene expression profile of gastric carcinoma: identification of genes and tags potentially involved in invasion, metastasis, and carcinogenesis by serial analysis of gene expression. Cancer Res 2004, 64:2397-2405.

8. Wu WK, Cho CH, Lee CW, Fan D, Wu K, Yu J, Sung JJ: Dysregulation of cellular signaling in gastric cancer. Cancer Lett 2010, 295:144-153.

9. Staudt LM: Oncogenic activation of NF-kappaB. Cold Spring Harb Perspect Biol 2010, 2:a000109.

10. Di Leva G, Croce CM: Roles of small RNAs in tumor formation. Trends Mol Med 2010, 16:257-267.

11. Volinia S, Calin GA, Liu CG, Ambs S, Cimmino A, Petrocca F, Visone R, lorio $M$, Roldo C, Ferracin M, et al: A microRNA expression signature of human solid tumors defines cancer gene targets. Proc Natl Acad Sci U S A 2006, 103:2257-2261.

12. Ueda T, Volinia S, Okumura H, Shimizu M, Taccioli C, Rossi S, Alder H, Liu CG, Oue N, Yasui W, et al: Relation between microRNA expression and progression and prognosis of gastric cancer: a microRNA expression analysis. Lancet Oncol 2010, 11:136-146.

13. Guo J, Miao Y, Xiao B, Huan R, Jiang Z, Meng D, Wang Y: Differential expression of microRNA species in human gastric cancer versus nontumorous tissues. J Gastroenterol Hepatol 2009, 24:652-657.

14. Bartel DP: MicroRNAs: genomics, biogenesis, mechanism, and function. Cell 2004, 116:281-297.

15. Ambros V: The functions of animal microRNAs. Nature $2004,431: 350-355$

16. Taganov KD, Boldin MP, Chang KJ, Baltimore D: NF-kappaB-dependent induction of microRNA miR-146, an inhibitor targeted to signaling proteins of innate immune responses. Proc Natl Acad Sci U S A 2006, 103:12481-12486.

17. Bhaumik D, Scott GK, Schokrpur S, Patil CK, Orjalo AV, Rodier F, Lithgow GJ, Campisi J: MicroRNAs miR-146a/b negatively modulate the senescenceassociated inflammatory mediators IL-6 and IL-8. Aging (Albany NY) 2009, 1:402-411.

18. Hou J, Wang P, Lin L, Liu X, Ma F, An H, Wang Z, Cao X: MicroRNA-146a feedback inhibits RIG-I-dependent Type I IFN production in macrophages by targeting TRAF6, IRAK1, and IRAK2. J Immunol 2009, 183:2150-2158.

19. Williams AE, Perry MM, Moschos SA, Larner-Svensson HM, Lindsay MA: Role of miRNA-146a in the regulation of the innate immune response and cancer. Biochem Soc Trans 2008, 36:1211-1215.

20. Li L, Chen XP, Li YJ: MicroRNA-146a and human disease. Scand J Immunol 2010, 71:227-231.

21. Tchernitsa O, Kasajima A, Schafer R, Kuban RJ, Ungethum U, Gyorffy B, Neumann U, Simon E, Weichert W, Ebert MP, Rocken C: Systematic evaluation of the miRNA-ome and its downstream effects on mRNA expression identifies gastric cancer progression. J Pathol 2010, 222:310-319.

22. Kogo R, Mimori K, Tanaka F, Komune S, Mori M: Clinical significance of miR-146a in gastric cancer cases. Clin Cancer Res 2011, 17:4277-4284.

23. Hou Z, Xie L, Yu L, Qian X, Liu B: MicroRNA-146a is down-regulated in gastric cancer and regulates cell proliferation and apoptosis. Med Oncol 2012, 29:886-892.

24. Li X, Zhang Y, Zhang H, Liu X, Gong T, Li M, Sun L, Ji G, Shi Y, Han Z, Han S, Nie Y, Chen X, Zhao Q, Ding J, Wu K, Daiming F: miRNA-223 promotes gastric cancer invasion and metastasis by targeting tumor suppressor EPB41L3. Mol Cancer Res 2011, 9:824-833.

25. Friis-Hansen L, Rieneck K, Nilsson HO, Wadstrom T, Rehfeld JF: Gastric inflammation, metaplasia, and tumor development in gastrin-deficient mice. Gastroenterology 2006, 131:246-258.
26. Wen J, Parker BJ, Jacobsen A, Krogh A: MicroRNA transfection and AGObound CLIP-seq data sets reveal distinct determinants of miRNA action. RNA 2011, 17:820-834.

27. Grabiner BC, Blonska M, Lin PC, You Y, Wang D, Sun J, Darnay BG, Dong C, Lin $X$ : CARMA3 deficiency abrogates $G$ protein-coupled receptor-induced NF-\{kappa\}B activation. Genes Dev 2007, 21:984-996.

28. Welteke V, Eitelhuber A, Duwel M, Schweitzer K, Naumann M, Krappmann D: COP9 signalosome controls the Carma1-Bcl10-Malt1 complex upon Tcell stimulation. EMBO Rep 2009, 10:642-648.

29. Sun W, Yang J: Molecular basis of lysophosphatidic acid-induced NFkappaB activation. Cell Signal 2010, 22:1799-1803.

30. Boldin MP, Taganov KD, Rao DS, Yang L, Zhao JL, Kalwani M, Garcia-Flores Y, Luong M, Devrekanli A, Xu J, et al: miR-146a is a significant brake on autoimmunity, myeloproliferation, and cancer in mice. J Exp Med 2011, 208:1189-1201.

31. Bhaumik D, Scott GK, Schokrpur S, Patil CK, Campisi J, Benz CC: Expression of microRNA-146 suppresses NF-kappaB activity with reduction of metastatic potential in breast cancer cells. Oncogene 2008, 27:5643-5647.

32. Sasaki N, Morisaki T, Hashizume K, Yao T, Tsuneyoshi M, Noshiro H, Nakamura K, Yamanaka T, Uchiyama A, Tanaka M, Katano M: Nuclear factorkappaB p65 (RelA) transcription factor is constitutively activated in human gastric carcinoma tissue. Clin Cancer Res 2001, 7:4136-4142.

33. Ooi CH, Ivanova T, Wu J, Lee M, Tan IB, Tao J, Ward L, Koo JH, Gopalakrishnan V, Zhu Y, et al: Oncogenic pathway combinations predict clinical prognosis in gastric cancer. PLoS Genet 2009, 5:e1000676.

34. Lee MH, Zhao R, Phan L, Yeung SC: Roles of COP9 signalosome in cancer. Cell Cycle 2011, 10:3057-3066.

35. Su H, Huang $W$, Wang $X$ : The COP9 signalosome negatively regulates proteasome proteolytic function and is essential to transcription. Int $J$ Biochem Cell Biol 2009, 41:615-624.

36. Lei D, Li F, Su H, Tian Z, Ye B, Wei N, Wang X: COP9 signalosome subunit 8 is required for postnatal hepatocyte survival and effective proliferation. Cell Death Differ 2011, 18:259-270.

37. Murray D, Horgan G, Macmathuna P, Doran P: NET1-mediated RhoA activation facilitates lysophosphatidic acid-induced cell migration and invasion in gastric cancer. Br J Cancer 2008, 99:1322-1329.

38. Li N, Xu X, Xiao B, Zhu ED, Li BS, Liu Z, Tang B, Zou QM, Liang HP, Mao XH: H. pylori related proinflammatory cytokines contribute to the induction of miR-146a in human gastric epithelial cells. Mol Biol Rep 2012, 39:4655-4661.

39. Ben-Baruch A: Inflammation-associated immune suppression in cancer: the roles played by cytokines, chemokines and additional mediators. Semin Cancer Biol 2006, 16:38-52

40. Dirkx AE, Oude Egbrink MG, Wagstaff J, Griffioen AW: Monocyte/macrophage infiltration in tumors: modulators of angiogenesis. J Leukoc Biol 2006, 80:1183-1196.

41. Oz-Arslan D, Ruscher W, Myrtek D, Ziemer M, Jin Y, Damaj BB, Sorichter S, Idzko M, Norgauer J, Maghazachi AA: IL-6 and IL-8 release is mediated via multiple signaling pathways after stimulating dendritic cells with lysophospholipids. J Leukoc Biol 2006, 80:287-297.

42. Chen SU, Chou CH, Lee H, Ho CH, Lin CW, Yang YS: Lysophosphatidic acid up-regulates expression of interleukin- 8 and -6 in granulosa-lutein cells through its receptors and nuclear factor-kappaB dependent pathways: implications for angiogenesis of corpus luteum and ovarian hyperstimulation syndrome. J Clin Endocrinol Metab 2008, 93:935-943.

43. Baud V, Karin M: Is NF-kappaB a good target for cancer therapy? Hopes and pitfalls. Nat Rev Drug Discov 2009, 8:33-40.

44. He H, Jazdzewski K, Li W, Liyanarachchi S, Nagy R, Volinia S, Calin GA, Liu CG, Franssila K, Suster $S$, et al: The role of microRNA genes in papillary thyroid carcinoma. Proc Natl Acad Sci U S A 2005, 102:19075-19080.

45. Wang X, Tang S, Le SY, Lu R, Rader JS, Meyers C, Zheng ZM: Aberrant expression of oncogenic and tumor-suppressive microRNAs in cervical cancer is required for cancer cell growth. PLOS One 2008, 3:e2557.

46. Pacifico F, Crescenzi E, Mellone S, lannetti A, Porrino N, Liguoro D, Moscato F, Grieco M, Formisano S, Leonardi A: Nuclear factor-\{kappa\}B contributes to anaplastic thyroid carcinomas through up-regulation of miR-146a. J Clin Endocrinol Metab 2010, 95:1421-1430.

47. Schweitzer K, Naumann M: Control of NF-kappaB activation by the COP9 signalosome. Biochem Soc Trans 2010, 38:156-161.

48. Dorsam RT, Gutkind JS: G-protein-coupled receptors and cancer. Nat Rev Cancer 2007, 7:79-94.

49. Sun J: CARMA3: A novel scaffold protein in regulation of NF-kappaB activation and diseases. World J Biol Chem 2010, 1:353-361. 
50. Hayden MS, Ghosh S: Signaling to NF-kappaB. Genes Dev 2004, 18:2195-2224.

51. Mestdagh P, Bostrom AK, Impens F, Fredlund E, Van Peer G, De Antonellis $P$, von Stedingk K, Ghesquiere B, Schulte S, Dews M, et al: The miR-17-92 microRNA cluster regulates multiple components of the TGF-beta pathway in neuroblastoma. Mol Cell 2010, 40:762-773.

52. Papagiannakopoulos T, Shapiro A, Kosik KS: MicroRNA-21 targets a network of key tumor-suppressive pathways in glioblastoma cells. Cancer Res 2008, 68:8164-8172.

53. Tsujimoto $H$, Ono S, Ichikura T, Matsumoto $Y$, Yamamoto J, Hase K: Roles of inflammatory cytokines in the progression of gastric cancer: friends or foes? Gastric Cancer 2010, 13:212-221.

54. Langowski JL, Zhang X, Wu L, Mattson JD, Chen T, Smith K, Basham B, McClanahan T, Kastelein RA, Oft M: IL-23 promotes tumour incidence and growth. Nature 2006, 442:461-465.

55. Zhang B, Rong G, Wei H, Zhang M, Bi J, Ma L, Xue X, Wei G, Liu X, Fang G: The prevalence of Th17 cells in patients with gastric cancer. Biochem Biophys Res Commun 2008, 374:533-537.

56. Cao R, Bjorndahl MA, Religa P, Clasper S, Garvin S, Galter D, Meister B, Ikomi $F$, Tritsaris K, Dissing S, et al: PDGF-BB induces intratumoral lymphangiogenesis and promotes lymphatic metastasis. Cancer Cell 2004, 6:333-345.

57. Ostman A, Augsten M: Cancer-associated fibroblasts and tumor growthbystanders turning into key players. Curr Opin Genet Dev 2009, 19:67-73.

58. Waugh DJ, Wilson C: The interleukin-8 pathway in cancer. Clin Cancer Res 2008, 14:6735-6741.

59. Mancino A, Lawrence T: Nuclear factor-kappaB and tumor-associated macrophages. Clin Cancer Res 2010, 16:784-789.

60. Mantovani A, Schioppa T, Porta C, Allavena P, Sica A: Role of tumorassociated macrophages in tumor progression and invasion. Cancer Metastasis Rev 2006, 25:315-322.

61. Nicklas W, Baneux P, Boot R, Decelle T, Deeny AA, Fumanelli M, Illgen-Wilcke $B$ : Recommendations for the health monitoring of rodent and rabbit colonies in breeding and experimental units. Lab Anim 2002, 36:20-42.

62. Frankel LB, Christoffersen NR, Jacobsen A, Lindow M, Krogh A, Lund AH: Programmed cell death 4 (PDCD4) is an important functional target of the microRNA miR-21 in breast cancer cells. J Biol Chem 2008, 283:1026-1033.

63. Jacobsen A, Wen J, Marks DS, Krogh A: Signatures of RNA binding proteins globally coupled to effective microRNA target sites. Genome Res 2010, 20:1010-1019.

64. Jorgensen S, Baker A, Moller S, Nielsen BS: Robust one-day in situ hybridization protocol for detection of microRNAs in paraffin samples using LNA probes. Methods 2010, 52:375-381.

65. Kuhn DE, Martin MM, Feldman DS, Terry AV Jr, Nuovo GJ, Elton TS: Experimental validation of miRNA targets. Methods 2008, 44:47-54

66. Cowland JB, Sorensen OE, Sehested M, Borregaard N: Neutrophil gelatinase-associated lipocalin is up-regulated in human epithelial cells by IL-1 beta, but not by TNF-alpha. J Immunol 2003, 171:6630-6639.

67. Boyum A: Separation of leukocytes from blood and bone marrow. Introduction. Scand J Clin Lab Invest Suppl 1968, 97:7.

\section{Submit your next manuscript to BioMed Central and take full advantage of:}

- Convenient online submission

- Thorough peer review

- No space constraints or color figure charges

- Immediate publication on acceptance

- Inclusion in PubMed, CAS, Scopus and Google Scholar

- Research which is freely available for redistribution 